\title{
Teaching of old historical mathematics problems with ICT tools
}

\author{
TüNDE KÁNTOR and AnNa Tóth
}

\begin{abstract}
The aim of this study is to examine how teachers can use ICT (information and communications technology) tools and the method of blended learning to teach mathematical problem solving. The new Hungarian mathematics curriculum (NAT) emphasizes the role of history of science, therefore we chose a topic from the history of mathematics, from the geometry of triangles: Viviani's Theorem and its problem field. We carried out our teaching experiments at a secondary school with 14-year-old students. Students investigated open geometrical problems with the help of a dynamic geometric software (GeoGebra). Their research work was similar to the historical way.
\end{abstract}

Key words and phrases: Viviani, geometry of triangles, problem field, open-ended problems, GeoGebra, blended learning, ICT tools.

ZDM Subject Classification: A30, C30, G10, D40, U50.

\section{Introduction}

In 2013 at the ProMath Conference (Eger) in the lecture 'Historical aspects in teaching mathematics' (Kántor, 2013) a teaching material was presented for students of secondary schools. We developed it for the students of normal classes (Part I-II), for students with high ability (Part III-VIII) and for the teachers we gave a guideline. We carried out our experiments principally using the traditional methods, but we formulated the posed problems as open-ended problems and created the problem field of Viviani's Theorem. We decided to repeat the investigation of the problem field of Viviani's Theorem by using modern techniques, with netbooks and dynamic software (GeoGebra). 
Our goals were:

1. To impact positively the students attitude about geometry.

2. To provide historical problems to discover theorems from the past.

3. To provide students with good and interesting problems.

4. To improve the students' self-confidence in using dynamic softwares.

5. To apply and develop the students' creativity.

6. To integrate computer technologies into school-practice.

7. To observe how and why new technologies influence the mathematics education and how can we combine the new technology and the traditional methods.

8. To observe the teacher's new role.

This article illustrates some experiences of blended learning from the viewpoint of solving old historical problems. We implemented the learning environment in a 9th grade classroom of the Svetits Catholic Secondary School (Debrecen) with 20 girls. Their teacher was Anna Tóth. Ability and knowledge of our students were heterogeneous. We had a few very talented students and some weak learners, as well, but most of our students were average. We chose this class because they met in grade 8 with the GeoGebra program, they were able to apply it and to make some simple geometric constructions with its help. It was very important that this school had enough Samsung netbooks for the individual research work. The whole class worked on the problems of Viviani's problem field. We devoted two lessons for it. Students showed remarkable motivation in solving geometrical problems with the help of GeoGebra.

\section{Background}

\section{Aims by using historical aspects}

Viviani's Theorem is suitable to illustrate the derivation of a problem field, to build new concepts, to generalize theorems. In our previous teaching material (Kántor, 2013) there were easier questions for investigation in the classroom for the less talented students, and there were also harder problems aimed at advanced students. We intended to improve problem solving and problem posing abilities of our students that are essential for teaching mathematics. We carried out experiments using history of mathematics in the classroom. We started with an 
important property of the regular triangle and with variations of the conditions. We solved a lot a of problems.

\section{Methods}

a) We applied open-ended problems. We leave some room for the problem solver to formulate their findings. An open-ended problem generally has several correct answers. So students can create their own mathematical ideas.

b) Our applied instructional method was blended learning. Blended learning is an instructional method in which students learn at least in parts through delivery of content and instruction via digital media with some element of student control over time, and face-to-face classroom methods are combined with computer mediated activities (Friesen, Norm, 2012). Our students worked individually on the posed problems solving it on their netbooks with the software GeoGebra. The teacher directed the instruction and followed with attention their digital work too.

c) We used the traditionally good learning methods for solving geometrical problems in the new digital environment as drawing figures, measuring distances, variations of data, discussions, argumentations, examples and their refutations (Lakatos, 1998).

\section{The teaching material of the problem field of Viviani's Theorem}

We have chosen the topic of the problem field from the history of mathematics, from the geometry of triangles: Viviani's Theorem and its generalizations.

Viviani's Theorem. For any point $P$ inside an equilateral triangle $A B C$ the sum $s$ of the length of the perpendiculars $d_{1}, d_{2}, d_{3}$ from the point $P$ to the sides is equal to the altitude $h$.

T. Kántor worked out a worksheet for the students and she gave it to the teacher. She formulated five open problems and the teacher chose four problems from it.

- We started from constructing an equilateral triangle $A B C$ and measuring its altitude with applying GeoGebra (Problem 1).

- We varied the placement of the point $P$ (Problem 2 and 4). 
- We changed the shape of the equilateral triangle to isosceles triangle (Problem $3)$.

- We posed the same questions as in the previous problems (Problem 4).

- Problem 5 was Viviani's Theorem, formulated as a research problem. Students have to investigate the properties with GeoGebra. After the research work and summarizing the results the teacher made the traditional proof by co-operating with the students.

The problem field of Viviani's Theorem

Problem 1. Construct an equilateral triangle $A B C$. Measure the length $h$ of its altitudes!

Problem 2. Let $P$ be a point on a side of the former triangle $A B C$. The length of the perpendiculars from the point $P$ to the sides are $d_{1}, d_{2}$. What can you say about the sum $s=d_{1}+d_{2}$ ? Construct a figure and make more measures while you change the position of the point $P$. Compose your conjecture! Summarize your results!

Problem 3. Construct an isosceles triangle $A B C$. Measure the length of its altitudes!

Problem 4. Let $P$ be a point on the base of the former isosceles triangle $A B C$. The length of the perpendiculars from the point $P$ to the sides are $d_{1}, d_{2}$. What can you say about the sum $s=d_{1}+d_{2}$ ? Construct a figure and make more measures while you change the position of the point $P$. Compose your conjecture! Summarize your results!

Problem 5. Let be given an equilateral triangle $A B C$ and an arbitrary point $P$ inside of the triangle $A B C$. Construct $P D, P E, P F$, as segments from $P$ perpendicular to sides $B C, A C, A B$, respectively. Consider the sum $s=$ $P D+P E+P F$. Make a comparison between the sum $s$ and the length $h$ (Problem 1). What is your conjecture about the sum $s$ ? Make more measurements while you change the position of the point P. Compose your conjectures! Summarize your results! 


\section{Research questions}

In this research we wanted to investigate the characterization of students' geometric problem solving in an interactive environment based on dynamic software and open-ended activities and the influence of old historical problems on their activities. It was a case study. We observed:

- For the 'Digital Natives' it is natural to use computers, netbooks and dynamic software products to solve geometrical problems.

- The group of students could be devided into two parts: for some it is natural to solve problems only with modern techniques and for the others it is obvious and more important to use the traditional methods in problem solving (Theory, proofs, argumentation).

\section{Implementation of the study}

\section{Circumstances}

The implementation started in September, 2013 in Svetits Catholic Nursery School, Primary School, Secondary School and Dormitory (Debrecen). We were teaching mathematics in groups with about 20 students. Students of a class were separated into two learning groups corresponding to their skills in mathematics. We carried out this research in a learning group with twenty 14-years-old girls of 9th grade. This was the group of students with better facilities. This fact does not mean that they were talented in mathematics but rather that they were hard-working. They prefered algorithmic tasks to problem solving. We devoted 2 lessons for Vivani's Theorem and its problem field. Students worked alone with Samsung netbooks and the teacher used a computer with projector.

\section{First lesson}

The teacher started with the first problem of the problem field of Viviani's Theorem. The problems were always presented verbally. Moreover, in this case she described the task in instalments. First she asked the girls to construct an equilateral triangle with the side length of $6 \mathrm{~cm}$. She did not mentioned any coordinates, because it would be a great opportunity to repeat how we construct an equilateral triangle. Then she asked them to construct altitudes of the triangle. In this step they repeated the definition and the construction of an altitude. Finally they made the length of the altitude $(5.2 \mathrm{~cm})$ visible with the software 
(Figure 1). The teacher suggested to check the result with calculation in their exercise books. Associated to their calculation they repeated the Pythagorean Theorem and the formula for the altitude of an equilateral triangle. Goals of this task were warming up and repetition of some basic mathematical facts and usage of GeoGebra.

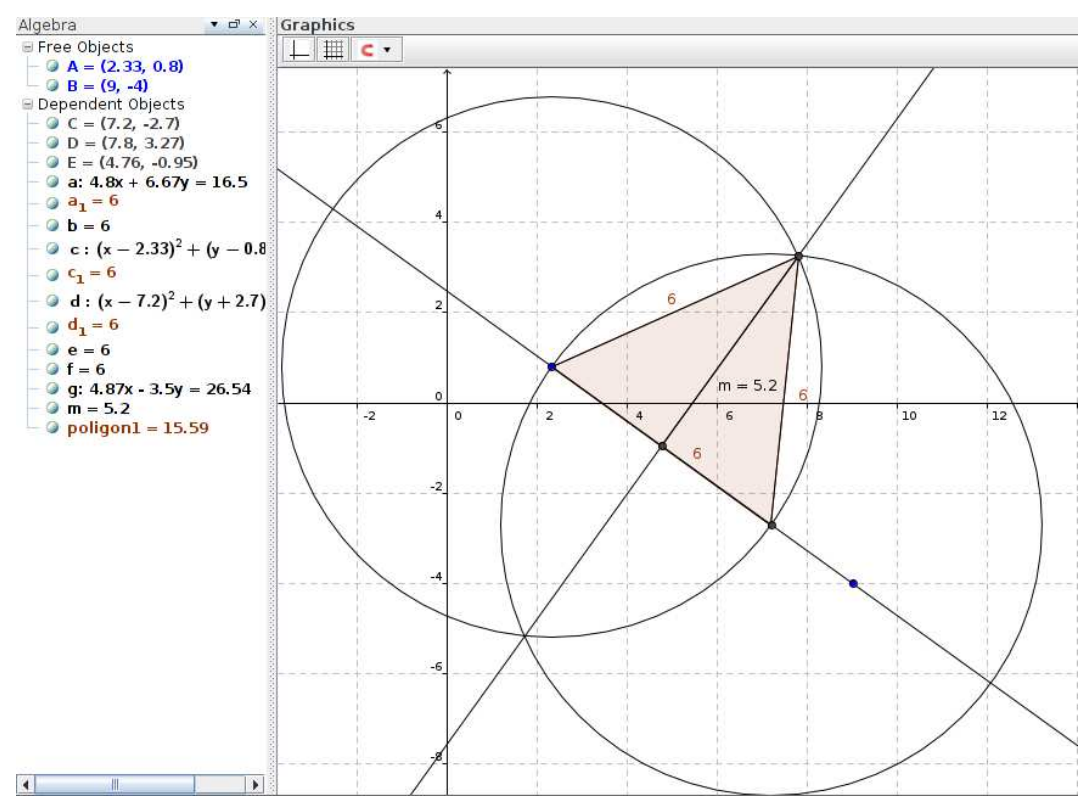

Figure 1. Screenshot of a student's computer after the first task

Secondly the teacher set out Problem 2. They worked with their former figures but first they needed to make auxiliary objects invisible. She described the problem in the above-mentioned way.

1. Pick up an arbitrary point $P$ on the side $A B$.

2. Construct the distance from point $P$ to the other sides and denote them by $d_{1}$ and $d_{2}$. (In this step we brushed up what the distance from a point to a line means.)

3. Show labels with the values of $d_{1}$ and $d_{2}$.

4. Change the position of point $P$ (Figure 2).

They found the correct solution soon, within 5 minutes. First they said that the sum of $d_{1}$ and $d_{2}$ is constant, so the teacher asked them to investigate what 
this constant equals to. After a few minutes thinking they answered this question, too (it is equal to the length of the altitude of the triangle). They made a figure in their exercise books and wrote the correct answer.

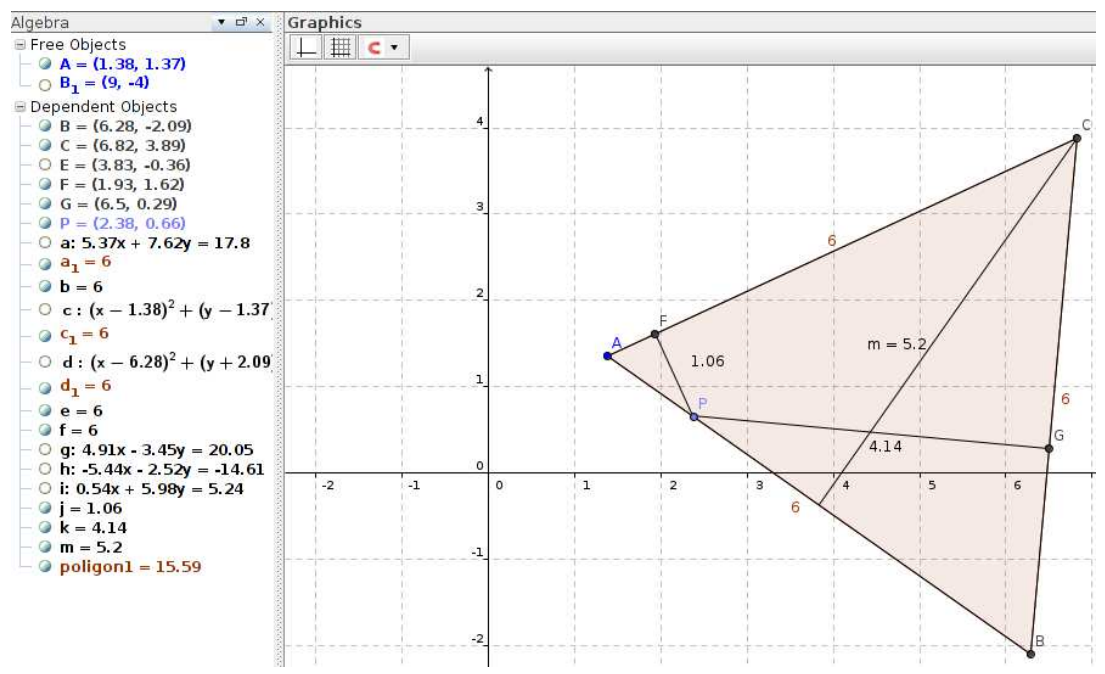

Figure 2. Screenshot of a student's computer after the second task

The first lesson ended with Problem 5. We introduced this task with the question: 'What do you think we can say if we choose an interior point of the former equilateral triangle and then we sum the distances of the point to the sides of the triangle?' Check it with your computer (Figure 3).

The first of all students solved this problem within 10 minutes and thereby she discovered Viviani's Theorem. The quick-working classmates and me helped the slower students. The students drew a figure, composed Viviani's Theorem and wrote it down in their exercise books. We had no time to prove the theorem, so the teacher gave it for home work: 'Try to prove our conjecture!' One possible proof will be calculating the area of the small and the large triangles. To help their students the teacher shared the information the students needed for the proof: 'separate the triangle to three small triangles.' Before the end of the first lesson the teacher asked the students' opinion for what kind of triangles does a similar proposition hold. They did not answer anything, finally after long silence Éva suggested the rectangular triangles. The teacher promised to check it, although this was not a good idea to the generalization. 


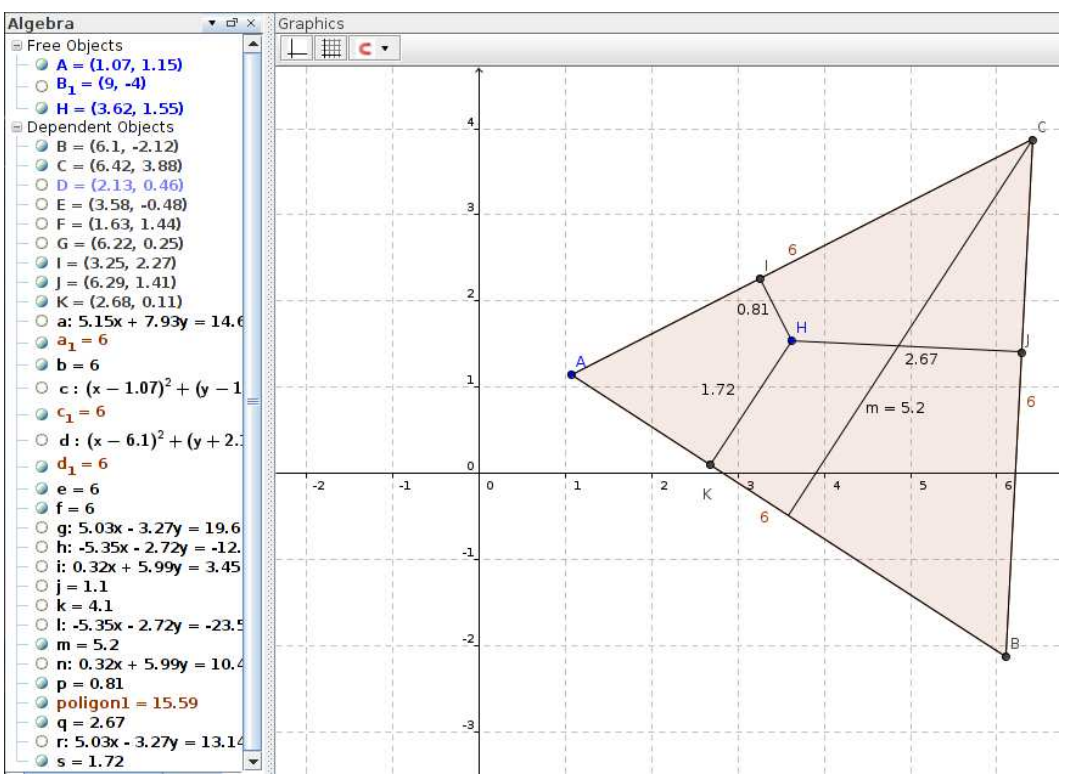

Figure 3. Screenshot of a student's computer after the third task

\section{Second lesson}

Nobody proved Viviani's Theorem at home, so they started the second lesson with the the specific proof by areas. They worked in the traditional way: the teacher asked questions and students dictated the proper answers. She wrote the answers on the black-board with chalk. Her questions were e.g.: 'What is the relation between the area of the large and the small triangles? How can we formulate this relation? How can we simplify this equation? How can we get the theorem from the following equation':

$$
\frac{a}{2} d_{1}+\frac{a}{2} d_{2}+\frac{a}{2} d_{3}=\frac{a}{2} m_{a}
$$

We got the suggestion from Kata: let us divide by $\frac{a}{2}$. We discussed why it does not always work and what else can we do. One student (Réka) wanted to know this method as well. The teacher showed how we can solve the problem with the help of factoring algebraic expressions. We could observe that on the common work (dictating the steps of the proof) some difficulties arose with the algebraic conversions. After the proof they turned to the suggestion of Éva, to investigate rectangular triangles. They constructed a rectangular triangle and investigated 
whether Viviani's Theorem is true or not. They realized soon that Viviani's Theorem is not valid (Figure 4).

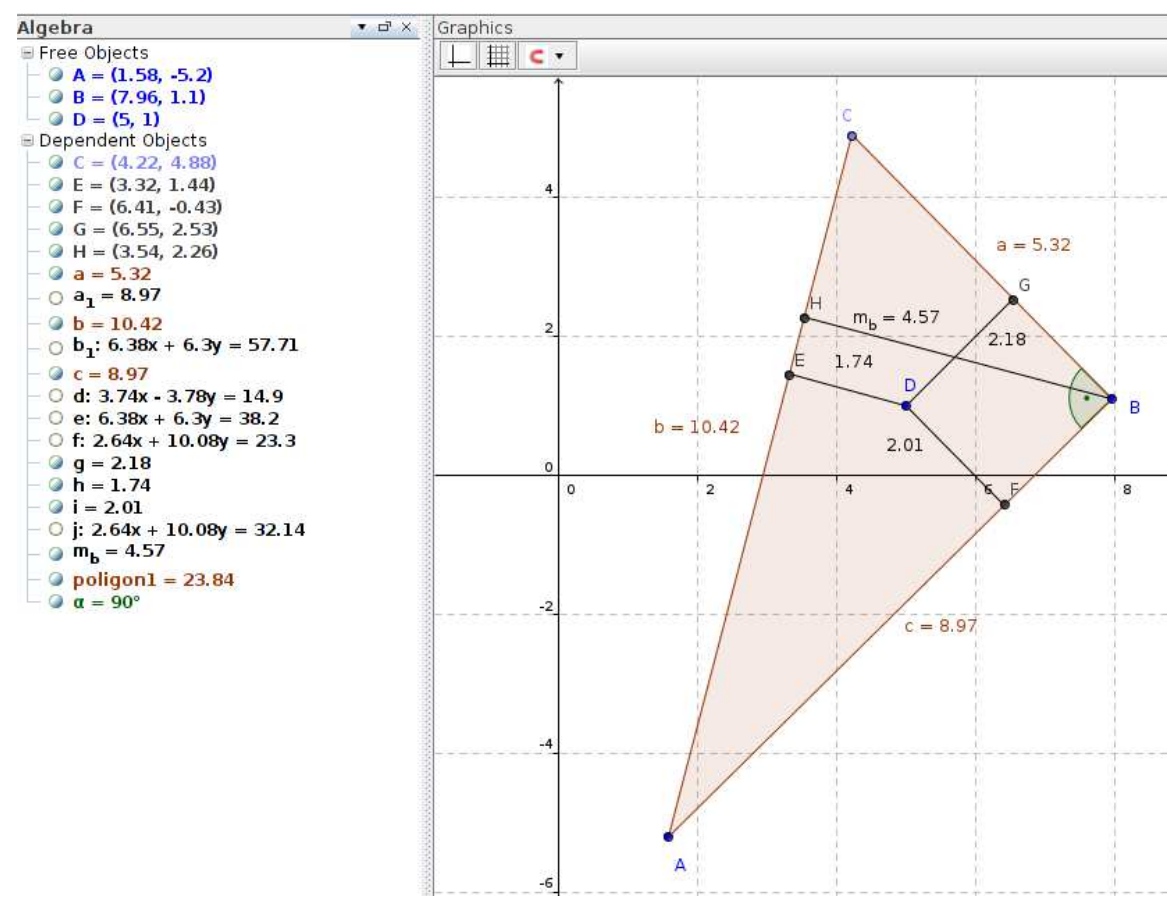

Figure 4. Screenshot of a student's computer after checking Viviani's Theorem for rectangular triangles

One student edited an almost isosceles rectangular triangle and she protested against our statement. Her opinion was that the theorem is almost true. We run out of time so the second lesson ended with this moment. On the following lesson they cleared up that a similar proposition is true for isosceles triangles if we pick up the point on its base (Problem 3).

\section{Results of the research}

It is very useful if the secondary school students can pose new problems, if they ask new questions after looking beyond the solved problem. We got different options from the students for locating the point $P$. They formulated new problems. The simplest problems were special extreme cases of Viviani's Theorem. 
But from Éva we got different option for the form of the triangle $A B C$, she proposed to investigate rectangular triangles. The teacher accepted her offer, and changed the problem to.

Problem a: What can we say about the sum $s$ if the point $P$ is on the hypotenuse of a rectangular triangle?

Problem b: What can we say about the sum $s$ if the point $P$ is on the hypotenuse of an isosceles rectangular triangle?

GeoGebra is interesting for lower classes. If we use dynamic geometry it is easier to construct, to measure, to test conjectures. The students like this method and worked with it with pleasure.

The investigated class separated into two parts. The bigger part, who were accustomed to computers and were better in informatics than in mathematics, had no problem in applying the new techniques. They worked easily, we can say naturally, with it. Two students had problems with applying the new techniques in their research work. Their problems did not come from applying them. They had problems with the individual research method. The teacher or their schoolmates helped them. There were only two students (Réka and Fanni) who understood and learnt the theoretical proof of Viviani's Theorem.

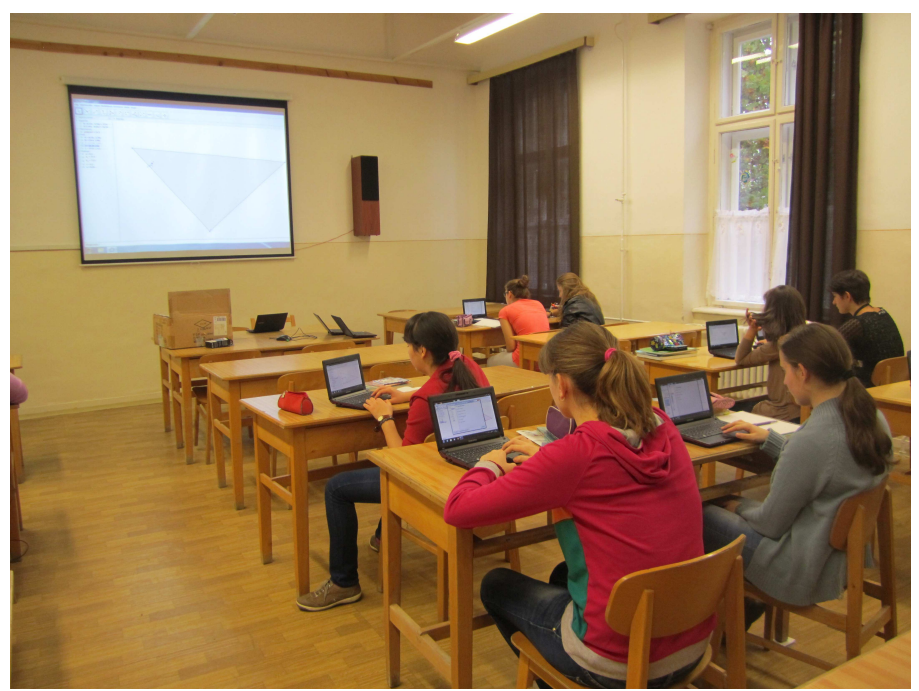

Figure 5. Students work on Viviani's Theorem with netbooks 


\section{Summary and conclusions}

We focused mostly on learning and teaching processes of blended learning to better understand the role of interactive technological environments in problem solving. Students are accustomed to interact with peers. We carried out experiments using historical problems of mathematics in the classroom. We started with the historical problem of Viviani. We dealt with an important property of the equilateral triangle and with variations of the conditions. We solved simple problems with the help of GeoGebra (see [4]). We pointed out that the teacher still plays an important role, not only with providing students with good problems, but on focusing on new technology, on investigating how to apply dynamic software (GeoGebra) in the mathematics teaching in a class, how the new technology influences the students' work and motivation. The research pointed out some defects of the Hungarian mathematics instruction (e.g. in a normal classroom we dont't have enough time for problem-based learning, discovery learning and for open learning environments, we dont't have enough ICT-tools). For the next school-year we recommended for problem solving the analogy of Viviani's Theorem in the space, make the transition from plane to space, i. e. the problem to calculate the sum of the distances of a point in a regular tetrahedron to its faces.

\section{References}

[1] N. Friesen, Report: Defining Blended Learning, 2012, http://learningspaces.org/papers/Defining_Blended_Learning_NF.pdf.

[2] F. Furinghetti and L. Radford, Historical Conceptual Developments and the Teaching of Mathematics: from Phylogenesis and Onthogenesis, Theory to Classroom Practice, in: Handbook of International Research in Mathematics Education, (Lyn D. English, ed.), Lawrence Erlbaum Assosiates, Publishers, Mahwah, New Jersey, 2002, 631-654.

[3] T. Kántor, History of Mathematics in the Secondary Schools, Matematika tanárképzés - matematika-tanártovábbképzés, Varga Tamás Napok előadásai, Calibra Kiadó, 1997, 51-68 (in Hungarian).

[4] T. Kántor, Historical aspects in teaching mathematics. Problem Solving in Mathematics Education, in: Proceedings of the 15th ProMath conference in Eger, (A. Ambrus, É. Vásárhelyi, eds.), Eötvös Loránd University, 2013, 80-94.

[5] I. Lakatos, Proofs and Refutations, Cambridge University Press, 1976, (Hungarian translation, 1998, Typotex, Budapest). 
TÜNDE KÁNTOR

UNIVERSITY OF DEBRECEN

DEBRECEN, HUNGARY

ANNA TÓTH

SVETITS CATHOLIC SECONDARY SCHOOL

DEBRECEN, HUNGARY

E-mail: tkantor@science.unideb.hu

E-mail: tothanna85@gmail.com

(Received June, 2015) 